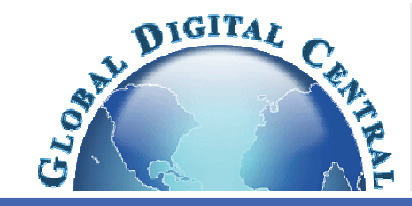

Frontiers in Heat and Mass Transfer

Available at www.ThermalFluidsCentral.org

\title{
FLOW BOILING OF WATER ON TITANIUM AND DIAMOND-LIKE CARBON COATED SURFACES IN A MICROCHANNEL
}

\author{
Hai Trieu Phan ${ }^{\mathrm{b}}$, Nadia Caney ${ }^{\mathrm{a}, \dagger}$, Philippe Marty ${ }^{\mathrm{a}}$, Stéphane Colasson ${ }^{\mathrm{b}}$, Jérôme Gavillet ${ }^{\mathrm{b}}$ \\ ${ }^{a}$ Université Joseph Fourier, LEGI, BP 53, 38041 Grenoble Cedex 9, France \\ ${ }^{b}$ LITEN, CEA Grenoble, 17 rue des martyrs, 38054 Grenoble Cedex 9, France
}

\section{ABSTRACT}

Experiments were performed to study the effects of surface wettability on flow boiling of water at atmospheric pressure. The test channel is a single rectangular channel $0.5 \mathrm{~mm}$ high, $5 \mathrm{~mm}$ wide and $180 \mathrm{~mm}$ long. The mass flux was set at 100 and $120 \mathrm{~kg} / \mathrm{m}^{2} \mathrm{~s}$ and the base heat flux was varied from 30 to $80 \mathrm{~kW} / \mathrm{m}^{2}$. Water enters the test channel under subcooled conditions. The sample surfaces are titanium (Ti) and diamond-like carbon (DLC) surfaces having a contact angle of $49^{\circ}$ and $63^{\circ}$, respectively. The experimental results show different flow patterns that impact the heat transfer significantly. Compared to the Ti surface, the DLC surface shows a deterioration of $10 \%$ in heat transfer.

Keywords: boiling, contact angle, nanocoating, wettability
\end{abstract}

\section{INTRODUCTION}

Microchannels and minichannels are channels with small hydraulic diameters which are especially desirable for size reduction of heat exchange devices in microelectronic industry for example. In order to distinguish between macro and microscale flow boiling, the threshold to confined bubble flow is one of the most widely used criterions. Following the classification by Kew and Cornwell (1997), channels are classified as microchannels if $C o \geq 0.5$, where $C o$ is the confinement number defined as:

$$
C o=\left[\frac{\sigma}{g\left(\rho_{l}-\rho_{v}\right) D_{h}^{2}}\right]^{1 / 2}
$$

Kandlikar and Grande (2003) suggested another classification based on the hydrodynamic diameter: conventional channels $\left(D_{h}>3 \mathrm{~mm}\right)$, minichannels $\left(200 \mu \mathrm{m}<D_{h}<3 \mathrm{~mm}\right)$ and micro-channels $\left(D_{h}<200\right.$ $\mu \mathrm{m})$.

In microchannel flow boiling, the heat transfer coefficient can significantly decrease at low values of vapour quality due to intermittent dryout, which refers to an unstable breakdown of the liquid film in contact with the wall (Caney et al., 2006, Madrid et al., 2007, Ali et al., 2009). Intensification of the heat transfer coefficient and delay of the intermittent dryout are two main objectives of research in recent years (Thome, 2004).

At small scales, capillary effects become important and may play a significant role in the heat transfer mechanism. For instance, Phan et al. (2009) showed that surface wettability affects the pool boiling heat transfer significantly. Modifying the surface wetting is thereby a reasonable solution to achieve the above objectives. Today, significant advances have been made in techniques of surface structuring at micro and nano scales, which enable significant modification of the surface wettability (see. Fig. 1).

In the present study, experiments were performed to determine the effects of surface wettability on the flow boiling heat transfer. The test channel is rectangular with hydraulic diameter of $0.96 \mathrm{~mm}$ and length of $180 \mathrm{~mm}$. The confinement number is equal to 2.6 , and hence the test channel is considered as microchannel according to Kew and Cornwell (1997) theory, but as minichannel according to Kandlikar and Grande (2003) classification. The local wall temperature and heat flux are directly measured. The channel geometry was precisely determined in order to reduce measurement uncertainties. The sample surfaces are produced by well-controlled processes to ensure that from one to another surface, only the wettability is modified as the other parameters remain constant.

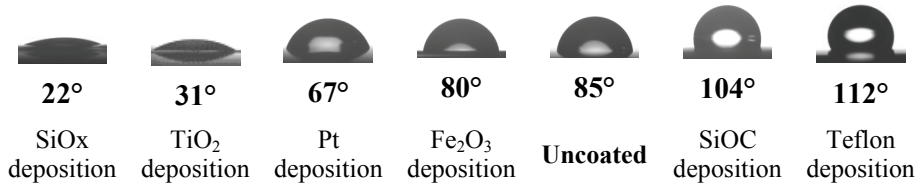

Fig. 1 Static contact angles water-droplets on coated and uncoated surfaces, (Phan et al., 2009).

\section{DESCRIPTION OF THE EXPERIMENTS}

\subsection{Sample-surface fabrication}

To determine the effects of surface wettability, it is necessary that all sample surfaces have the same geometry with only change in contact angle. In other words, they should have the same dimensions (length, width and thickness) and the same topography at microscale. The sample surfaces are thereby produced by deposition of nanoparticles through patterning masks using techniques of physical and chemical vapour depositions according to the following steps (see Fig. 2).

Step 1: deposition of titanium (Ti) layer. The base substrate is a Pyrex wafer of $200 \mathrm{~mm}$ diameter and $1.1 \mathrm{~mm}$ thickness. This layer is used as a heating element. It consists of a rectangular track corresponding to the testing area and pads for electrical connections.

Step 2: deposition of diamond-like carbon (DLC) layer. This layer is used for electrical insulation.

\footnotetext{
${ }^{\dagger}$ Corresponding author.Email: nadia.caney@ujf-grenoble.fr
} 
Step 3: deposition of nanoparticle layer. This layer enables modification of the surface wettability in a larger threshold. This layer will enable modification of the surface wettability in future works.

The testing area is $5 \mathrm{~mm}$ wide and $180 \mathrm{~mm}$ long (see Fig. 3). It is heated by Joule effect from the metallic layer. Electrical wires are fixed on the electrical pads by mechanical support. Current and voltages of different sections of the testing area are measured by Agilent $34970 \mathrm{~A}$ and a $0.01 \Omega$ shunt, which has an accurately known resistance for determination of current by measurement of voltage.

Once a sample surface is produced, stabilization of its deposition layers is made by annealing in a vacuum chamber at $300{ }^{\circ} \mathrm{C}$ for 3 hours. The local wall temperature at each section of the sample surface can be deduced from measurements of the electric resistance by using the Resistance/Temperature curve, which was previously established.

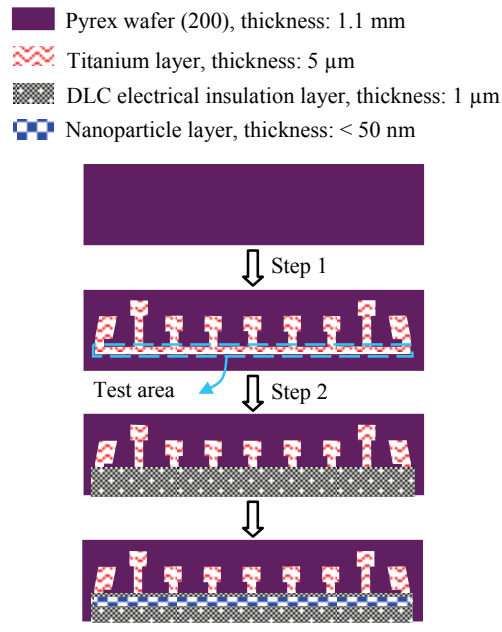

Fig. 2 Top view of fabrication procedure of sample surfaces.

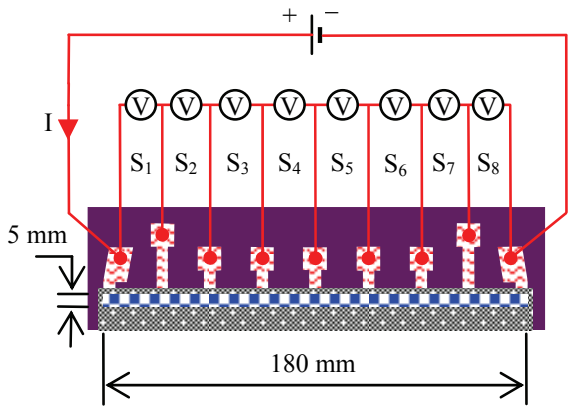

Fig. 3 Schematic view of electrical connexion.

\subsection{Experimental apparatus}

The channel is defined by putting a glass lid over the sample surface. This lid has a rectangular groove $5 \mathrm{~mm}$ wide, $0.5 \mathrm{~mm}$ deep and is bonded to the Pyrex wafer by vacuum aspiration (see Fig. 4). To prevent fluid leakage, silicone compound is placed around the external contact between the glass cap and the Pyrex wafer. The channel is thermally insulated with foam. Visualisation of the fluid flow can be made from the top of the glass lid.

The experimental setup is shown in Fig. 5. It consists of a test section, a condenser with a cooling bath, a liquid pump (ISMATEC MCP Z Z), a mass flowmeter (Micro Motion Elite MVD) and a pre- heater. A reservoir is used to store the fluid and to control the working pressure at atmospheric pressure.

The experimental facility is instrumented with an absolute pressure transducer ( 1 bar) to measure the pressure at the inlet of the test section, and a differential pressure transducer (100 mbar) to measure the pressure drop across the test section. K-type thermocouples are inserted at different locations to measure the bulk fluid temperature.

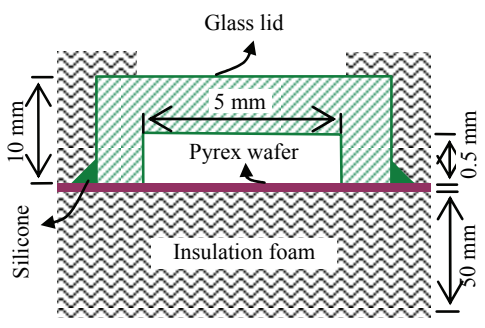

Fig. 4 Assembly of the test section.

\subsection{Experimental procedure}

Before each test point, degassing of water is made by boiling at saturated temperature $\left(100^{\circ} \mathrm{C}\right)$ for two hours. Then, the desired flow rate is established and the electrical power is raised in steps lasting a few minutes each until a new steady state is achieved. The mass flux was set at $100 \mathrm{~kg} / \mathrm{m}^{2} \mathrm{~s}$ and $120 \mathrm{~kg} / \mathrm{m}^{2} \mathrm{~s}$ and the base heat flux was varied from $30 \mathrm{~kW} / \mathrm{m}^{2}$ to $80 \mathrm{~kW} / \mathrm{m}^{2}$.

\section{DATA REDUCTION}

For a given test point, the local heat flux at section $i$ of the sample surface is calculated as:

$$
q_{i}=\frac{I V_{i}}{A_{h, i}}
$$

where $I$ is the current, $V_{i}$ is the voltage and $A_{h, i}$ is the area of section $i$. The local heat transfer coefficient is determined from the local wall to bulk temperature difference and the heat flux as:

$$
h_{i}=\frac{q_{i}}{T_{w, i}-T_{f, i}}
$$

Under subcooled conditions, the bulk temperature is calculated from the inlet temperature and the heat added to the test section:

$$
T_{f, i}=T_{f, i n}+\sum_{j=1}^{i} \frac{A_{h, j}\left(q_{j}-q_{\text {loss }}\right)}{\dot{m} C_{p, j}}
$$

where $q_{\text {loss }}$ is the flux of heat loss, which is mainly due to air convection near the test section and can be estimated by the energy balance in single-phase flow conditions.

The local saturation temperature, $T_{s, i}$, is determined by taking into account the drop in saturation temperature due to pressure drop, where the pressure drop is assumed to vary linearly along the test section. The variation of the vapour quality is calculated as:

$$
\Delta x_{i}=\frac{A_{h, i}\left(q_{i}-q_{\text {loss }}\right)-\dot{m} C_{p, i}\left(T_{s, i}-T_{f, i}\right)}{\dot{m} h_{l v, i}}
$$

where $h_{l v}$ is the latent heat of vaporisation. 


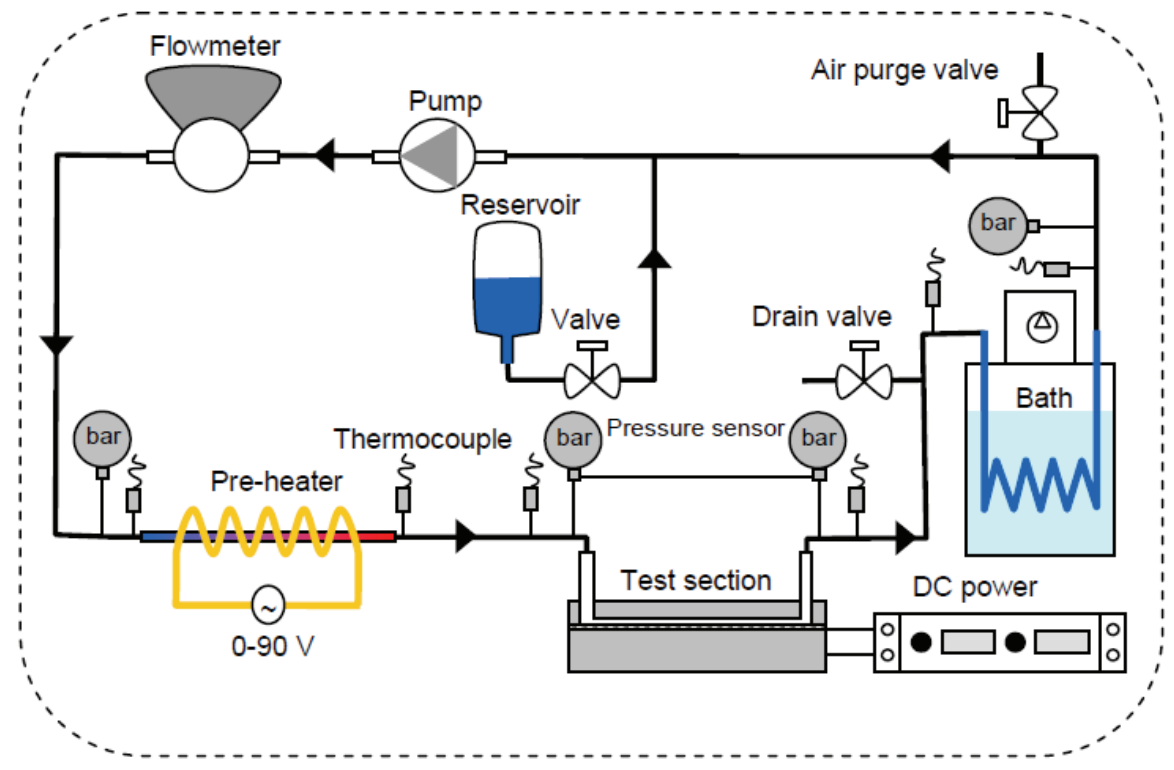

Fig. 5 Schematic view of the experimental apparatus.

Thermodynamic properties of water are calculated with the computer code REFPROP 7.0. Experimental parameters and operating conditions are summarized in Table 1 . The measurement uncertainties are estimated using the error propagation law suggested by Kline and McClintock (1953).

Table 1 Operating parameters and uncertainties

\begin{tabular}{lll}
\hline Parameter & Range & Uncertainty \\
\hline$D_{h}(\mathrm{~mm})$ & 0.96 & $\pm 0.02 \mathrm{~mm}$ \\
$G\left(\mathrm{~kg} / \mathrm{m}^{2} \mathrm{~s}\right)$ & 100 & $\pm 2 \%$ \\
$P_{\text {in }}(\mathrm{mbar})$ & 1000 & $\pm 0.1 \%$ \\
$P_{\text {in }}-P_{\text {out }}(\mathrm{mbar})$ & $0-100$ & $\pm 0.3 \%$ \\
$T_{s}\left({ }^{\circ} \mathrm{C}\right)$ & 100 & $\pm 0.2^{\circ} \mathrm{C}$ \\
$T_{w}\left({ }^{\circ} \mathrm{C}\right)$ & $100-120$ & $\pm 0.2{ }^{\circ} \mathrm{C}$ \\
$q(\mathrm{~W})$ & $0-500$ & $\pm 2 \%$ \\
$h\left(\mathrm{~kW} / \mathrm{m}^{2} \mathrm{~K}\right)$ & $3-30$ & $\pm 4-7 \%$ \\
$x$ & $-0.1-0.2$ & $\pm 2 \%$ \\
\hline
\end{tabular}

\section{SINGLE-PHASE FLOW VALIDATION TESTS}

Validation tests are made by using the titanium surface (made by step 1 in Section 2a). To validate the test facility and the test section, the first step was to perform energy balance tests with highly-subcooled water flow $\left(25^{\circ} \mathrm{C}\right.$ below the saturation temperature) at the inlet of the test section. The electrical heat loss from the sample surface to the fluid flow was less than $5 \%$ for base heat flux greater than $1 \mathrm{~W} / \mathrm{cm}^{2}$ and less than $3 \%$ for base heat flux greater than $2 \mathrm{~W} / \mathrm{cm}^{2}$. The electrical heat loss can be then neglected.

The second step was to perform single-phase liquid measurements of pressure loss and heat transfer to validate the measurement technique and the data reduction procedure. The fluid enters the test section at the ambient temperature $\left(20{ }^{\circ} \mathrm{C}\right)$ at $100 \mathrm{~kg} / \mathrm{m}^{2} \mathrm{~s}$. The results (see Fig. 6) show the evolution of the regular pressure loss with the Reynolds number. The experimental data show a relatively good agreement with the theoretical solutions of Shah and London (1978) (maximum deviation of 7\%). The evolution of the Nusselt number with the reduced flow length is calculated (see Fig. 7). A good agreement between the experimental and the theoretical data is also obtained, with only a maximum deviation of $5 \%$, even at low Reynolds numbers.

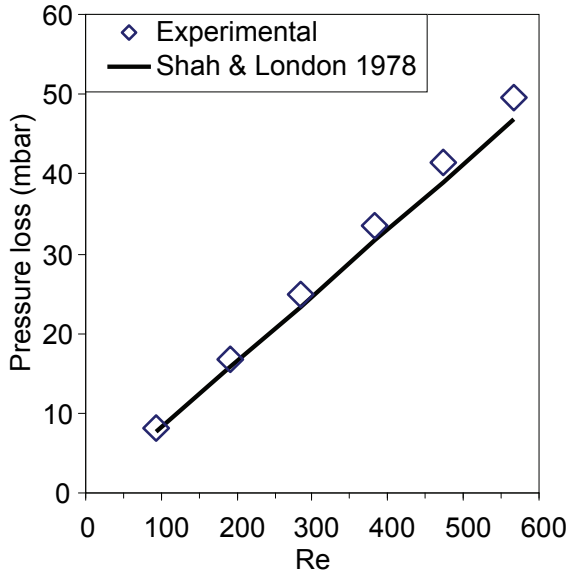

Fig. 6 Pressure loss vs. Reynolds number.

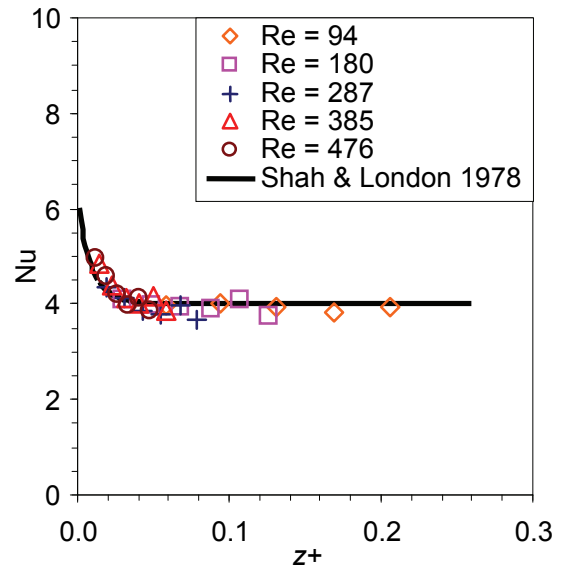

Fig. 7 Local Nusselt number vs. reduced length.

\section{FLOW BOILING EXPERIMENTAL RESULTS}

The contact angles of water on the sample surfaces were measured by using the sessile drop technique with KRÜSS EasyDrop systems, as shown in Fig. 8. Measurements were made in a cleanroom at room 
temperature. The Ti and DLC surfaces are both wetted (hydrophilic) and have static contact angles $(\theta)$ of $49^{\circ}$ and $63^{\circ}$, respectively.

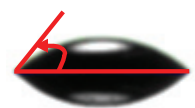

$49^{\circ}$

Ti surface

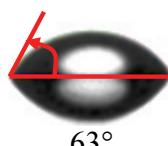

DLC surface
Fig. 8 Static contact angles of a water-droplet on the sample surfaces at room temperature.

Fig. 9 shows the evolution of the heat transfer coefficient as a function of the vapour quality on different sample surfaces. In boiling condition, the heat transfer coefficient is in the range from 5000 to $30000 \mathrm{~W} / \mathrm{m}^{2} \mathrm{~K}$. This is in agreement with observations of Sobierska et al. (2007).

With a given heat flux, when boiling occurs, it is noticed that the heat transfer coefficient increases when the vapour quality increases. For a vapour quality between 0.005 and 0.015 , the heat transfer coefficient reaches its maximum value, and then decreases to a constant value. An increase in the heat flux leads to an increase in this constant value.

It is noticed that the mass flux has a slight effect on the heat transfer coefficient. For both surfaces, at $120 \mathrm{~kg} / \mathrm{m}^{2} \mathrm{~s}$, the best heat transfer coefficient is obtained with the maximum operating heat flux, which is about $80 \mathrm{~kW} / \mathrm{m}^{2}$. However, at $100 \mathrm{~kg} / \mathrm{m}^{2} \mathrm{~s}$, lower heat fluxes can give higher values of the maximum heat transfer coefficient. Especially, for DLC surface, the heat transfer coefficient reaches the maximum value of $25000 \mathrm{~W} / \mathrm{m}^{2} \mathrm{~K}$ when the heat flux is equal to 42 $\mathrm{kW} / \mathrm{m}^{2}$. This effect of mass flux may be due to the impact of nucleate boiling at low vapour qualities, which is frequently higher for a lower mass flux.

In general, the heat transfer coefficient on the DLC surface is lower than that on titanium surface (with an average degradation of about $10 \%$ ). This may be due to the lower wettability of DLC that leads to a thicker liquid film at the wall (Phan et al., 2009).

\section{DISCUSSION}

In order to clarify the boiling processes, images taken from the high speed camera were analysed. Fig. 10 shows the flow patterns on the titanium surface.

Three boiling flow patterns were identified: bubbly flow (BF), slug flow (SF) and semi-annular flow (SAF). The intermittent dryout was observed (by condensation of vapour on the top wall of the test channel) when the flow pattern changes from slug to semi-annular flow. The same flow patterns are observed with DLC surface as shown in Fig. 11.

The heat transfer coefficient significantly increases in the bubbly and slug flow configurations. Its maximum value would be obtained in slug flow when the liquid layer thickness reaches its minimum value. The heat transfer deterioration occurs when elongated bubbles in slug flow coalesce and form some churning liquid zones at the wall. This can be explained by the presence of the intermittent dryout observed in the semi-annular flow, as well as the increase of liquid film thickness in wavy conditions.

\section{CONCLUSION}

The flow boiling heat transfer of water on nanostructured surfaces was determined. The experimental results show different flow patterns such as bubbly flow, slug flow, and semi-annular flow, which significantly impact the heat transfer. The general tendency of evolution of the heat transfer coefficient with the vapour quality is as follows: when boiling occurs, the heat transfer coefficient increases with the vapour quality. For a vapour quality between 0.005 and 0.015 , the heat transfer coefficient reaches its maximum value, and then decreases before remaining constant.
The DLC surface having a lower wettability than titanium shows a lower heat transfer coefficient (average degradation of 10\%). Experiments with a larger set of contact angle are being carried on to widely explore the effects of wettability on flow boiling heat transfer.
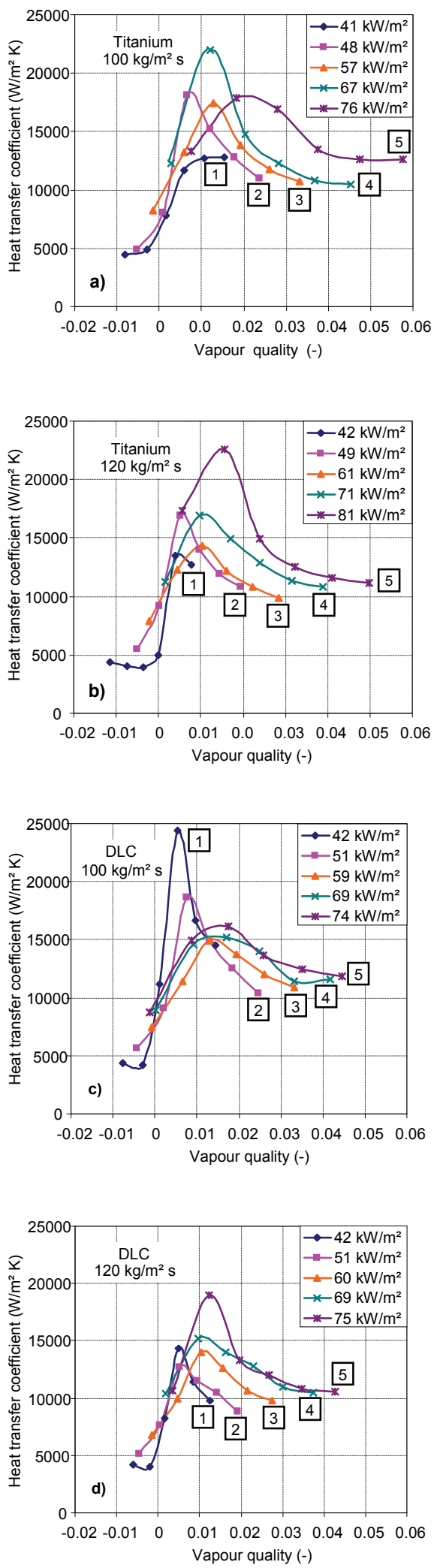

Fig. 9 Heat transfer coefficient vs. vapour quality on a) and b) titanium surface and c) and d) DLC surface. 

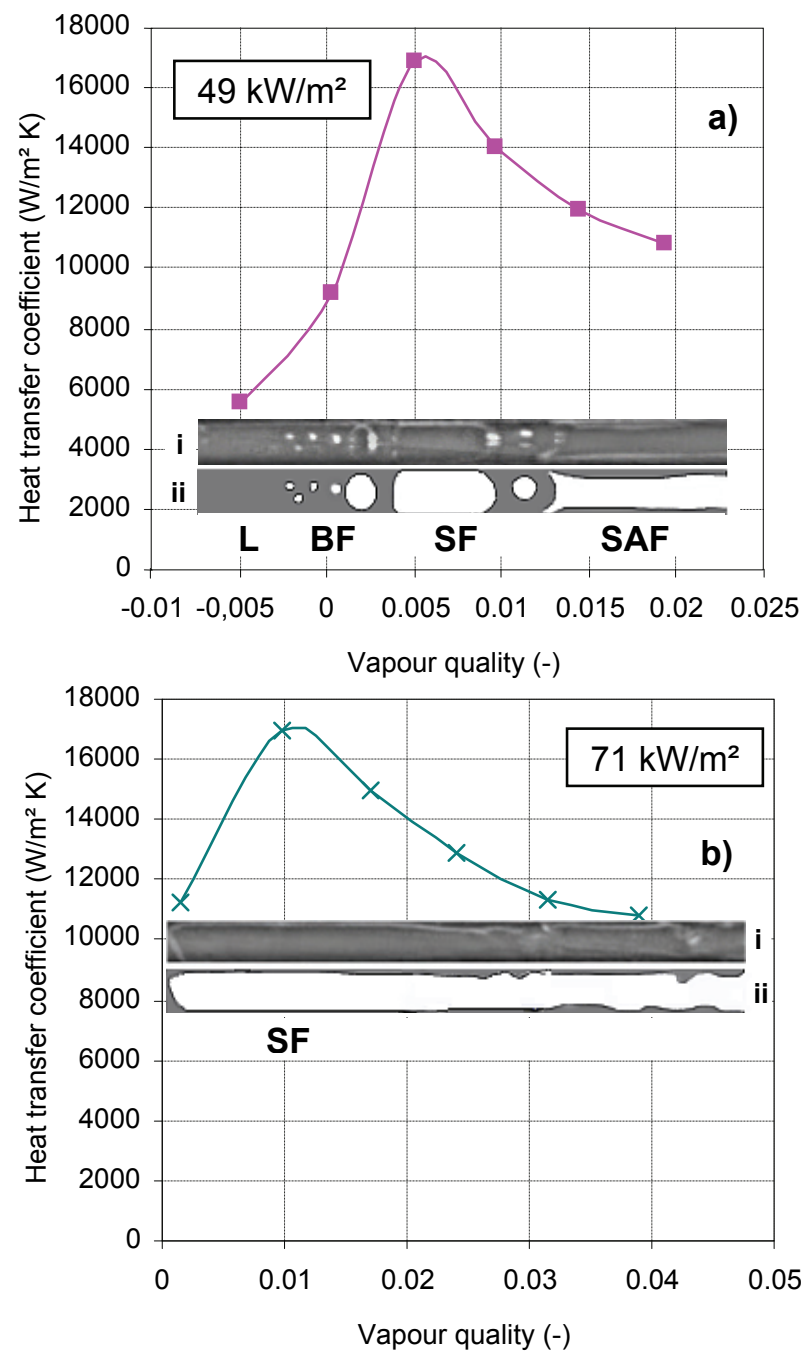

Fig. 10 Flow patterns on titanium surface at $120 \mathrm{~kg} / \mathrm{m}^{2} \mathrm{~s}$ with i) original image and ii) image with contour sharpening .

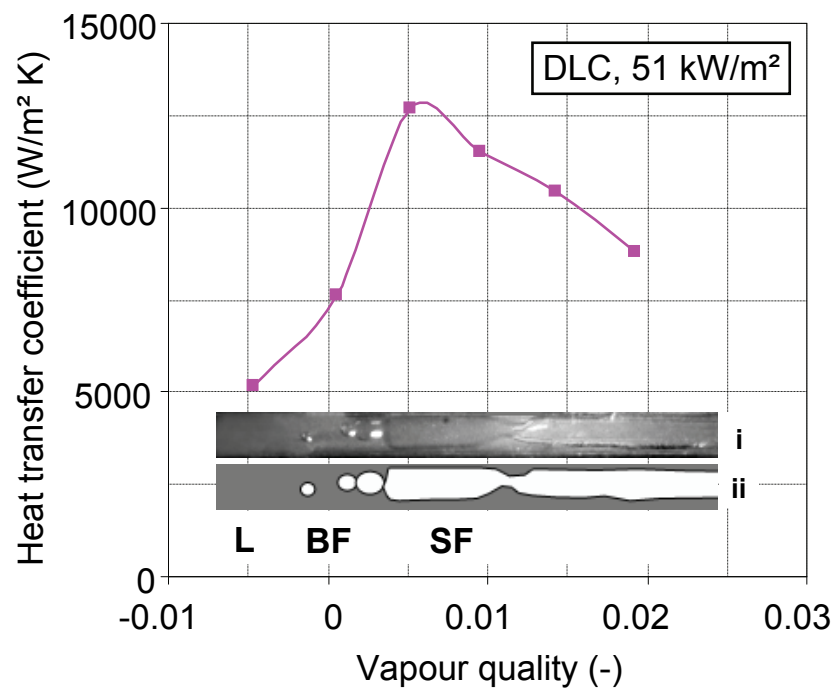

Fig. 11 Flow patterns on DLC surface at $120 \mathrm{~kg} / \mathrm{m}^{2} \mathrm{~s}$ with i) original image and ii) image with contour sharpening. 
Kew, P., and Cornwell, K., 1997, "Correlations for the prediction of boiling heat transfer in small-diameter channels", Applied Thermal Engineering, 17, 705-715.

doi:10.1016/S1359-4311(96)00071-3

Kline, S.J., and McClintock, F.A., 1953, "Describing uncertainties in single-sample experiments”, Mechanical Engineering, 75, 3-8.

Madrid, F., Caney, N., Marty, P., 2007, "Study of a vertical boiling flow in rectangular mini-channels", Heat Transfer Engineering, 28, 753-760.

doi: $10.1080 / 01457630701328445$

Phan, H. T., Caney, N., Marty, P., Colasson, S., Gavillet, J., 2009, "Surface wettability controlled by nanocoating: The effects on pool boiling heat transfer and nucleation mechanism", International Journal of Heat and Mass Transfer, 52, 5459-5471. doi:10.1016/j.ijheatmasstransfer.2009.06.032

Shah, R., and London, A., 1978, Laminar Flow Forced Convection in Ducts, Academic Press.

Sobierska, E., Kulenovic, R., Mertz, R., 2007, "Heat transfer mechanism and flow pattern during flow boiling of water in a vertical narrow channel- experimental results", International Journal of Thermal Sciences, 46, 1172-1181.

doi:10.1016/j.ijthermalsci.2007.06.011

Thome, J. R., 2004, "Boiling in microchannels: a review of experiment and theory", International Journal of Heat and Fluid Flow, 25, 128-139.

doi:10.1016/j.ijheatfluidflow.2003.11.005 